\title{
ERRATUM
}

Ryozo Imai • Michiya Koike • Keita Sutoh

Akira Kawakami · Atsushi Torada $\cdot$ Kiyoharu Oono

\section{Molecular characterization of a cold-induced plasma membrane protein gene from wheat}

Published online: 20 January 2006

(c) Springer-Verlag 2006

Mol Genet Genomics (2005). DOI: 10.1007/s00438-0050050-3

The list of authors appeared in the wrong order. The correct order should be: Michiya Koike, Keita Sutoh, Akira Kawakami, Atsushi Torada, Kiyoharu Oono, and Ryozo Imai ${ }^{\bowtie}$

The online version of the original article can be found at http:// dx.doi.org/10.1007/s00438-005-0050-3

R. Imai $(\bowtie) \cdot$ M. Koike $\cdot$ K. Sutoh · A. Kawakami $\cdot$ K. Oono Winter Stress Laboratory,

National Agricultural Research Center for Hokkaido Region,

Hitsujigaoka 1, 062-8555 Toyohira-ku, Sapporo, Japan

E-mail: rzi@affrc.go.jp

Fax: + 81-11-8579382

A. Torada $\cdot$ M. Koike

Hokkaido Green-Bio Institute, 069-1317 Naganuma,

Hokkaido, Japan

Fax: + 81-11-8579382 